\title{
Perancangan dan Implementasi Sistem Informasi Penumpang
}

\author{
Sinung Suakanto ${ }^{1}$, Herry Sitepu ${ }^{2}$, Daniel Hadi Wijaya ${ }^{3}$, Yoyok Gamaliel ${ }^{4}$, Dina Angela ${ }^{5}$ \\ Departemen Teknologi Informasi, Institut Teknologi Harapan Bangsa \\ Jl. Dipatiukur no. 80-84, Bandung, Jawa Barat, Indonesia
}

Email : ${ }^{1}$ sinung@ithb.ac.id, ${ }^{2}$ herry@ithb.ac.id, ${ }^{3}$ wijayadanie154@gmail.com, ${ }^{4}$ yoyok@ithb.ac.id, 5 dina_angela@ithb.ac.id

\begin{abstract}
Electric Railway (KRL) in Jabodetabek is one of the most reliable land transportation because it can carry passengers in large quantities. Timetables, fares, seat availability, travel time, and travel routes are the most needed information for KRL passengers. Currently, information technology has not been fully utilized to convey information to passengers, such as the process of information delivery is still with the help of officers at the station. The information is very necessary, such as to obtain certainty, reduce anxiety, and support the process of making travel decisions for passengers. This research will design and build a display system of KRL Commuter Line Jabodetabek passenger information by using ReactJS framework which will be applied to the kiosk display at every Commuter Line KRL station. Implementation of this passenger information system is expected to help operators work effectively and to help passengers know KRL information quickly and accurately.
\end{abstract}

Keywords: KRL Commuter Line, passsenger information system, display system, public transportation, train.

Abstrak: Kereta Rel Listrik (KRL) di Jabodetabek adalah salah satu transportasi darat yang paling diandalkan karena dapat mengangkut penumpang dalam jumlah banyak. Jadwal, tarif, ketersediaan tempat duduk, waktu tempuh, dan rute perjalanan merupakan informasi yang paling dibutuhkan oleh penumpang KRL. Saat ini teknologi informasi belum secara utuh dimanfaatkan untuk menyampaikan informasi kepada penumpang, seperti proses penyampaian informasi masih dengan bantuan petugas di stasiun. Informasi tersebut sangatlah diperlukan, seperti untuk memperoleh kepastian, mengurangi kecemasan dan mendukung proses pengambilan keputusan perjalanan bagi penumpang. Penelitian ini akan merancang dan membangun sistem display informasi penumpang KRL Commuter Line Jabodetabek dengan menggunakan ReactJS framework yang akan diterapkan pada display kiosk di setiap stasiun KRL Commuter Line. Implementasi dari sistem informasi penumpang ini diharapkan akan membantu operator agar lebih efektif dalam pekerjaannya dan membantu penumpang untuk mengetahui informasi KRL secara cepat dan tepat.

Kata kunci: KRL Commuter Line, sistem informasi penumpang, sistem display, transportasi publik, kereta api.

\section{PENDAHULUAN}

Saat ini transportasi memegang peranan yang sangat penting dan strategis dalam mendukung segala aspek kehidupan dan penghidupan, baik di bidang ekonomi, sosial-budaya, politik, maupun pertahanan dan keamanan negara. Oleh karena itu, informasi transportasi merupakan salah satu informasi yang dibutuhkan oleh masyarakat. Masyarakat membutuhkan informasi seperti jadwal, kedatangan, keberangkatan, estimasi waktu tempuh, dan lainnya.

Kereta Rel Listrik (KRL) merupakan salah satu moda transportasi darat yang dapat mengangkut penumpang dalam jumlah banyak. Informasi tentang kedatangan KRL saat ini masih menggunakan pengoperasian manual dengan bantuan informasi dari petugas yang ada di setiap stasiun. 
Operator mengisi data informasi ke dalam sistem setelah KRL akan tiba ke stasiun. Informasi yang diterima hanya informasi ketika KRL sudah tiba di stasiun. Masyarakat belum bisa mengetahui lebih detail mengenai posisi KRL yang dikehendaki, misalnya beberapa menit lagi kereta tersebut akan tiba, kereta saat ini sedang ada di mana, dan hal lainnya.

Oleh karena itu, dalam penelitian ini akan dirancang sebuah sistem informasi yang lebih detail sehingga masyarakat dapat lebih mudah mengetahui informasi tersebut. Sistem ini diharapkan dapat membuat pekerjaan lebih efektif sehingga penumpang dapat lebih mudah mengetahui informasi KRL. Dengan adanya informasi tersebut, diharapkan masyarakat terbantu dalam menggunakan KRL.

Hasil dari penelitian ini adalah membuat sistem informasi penumpang memanfaatkan data yang sudah ada agar masyarakat dapat menggunakan transportasi KRL dengan nyaman.

Manfaat dari penelitian ini adalah memudahkan masyarakat dalam beraktifitas menggunakan transportasi KRL. Sistem pengolahan informasi yang dapat membuat pekerjaan operator.

\section{KAJIAN PUSTAKA}

\subsection{Passenger Information System}

Passenger Information System (PIS) adalah sebuah metode atau teknologi untuk memberikan informasi kepada penumpang mengenai status moda transportasi tertentu. PIS merupakan salah satu elemen yang paling penting dari sistem transportasi modern. Passenger Information System diciptakan untuk mengurangi keterlibatan penumpang untuk mencari informasi, menghemat waktu dan meningkatkan kenyamanan. Cara-cara tradisional memberitahu penumpang perlahan-lahan memudar terlupakan dan digantikan oleh solusi lebih mudah, efisien dan dengan tingkat ruang lingkup informasi yang disampaikan lebih besar ("The-Alcatel-Lucent," 2016).

Matsumoto, Nakada, dan Azuma (2016) menyatakan sistem informasi penumpang saat ini terdiri dari:

1. Display informasi menggunakan layar LED untuk aplikasi indoor atau outdoor.

2. Drivers untuk pengawasan dan integrasi tiap perangkat.

3. Modul GPS digunakan untuk mengetahui lokasi aktual kendaraan.

4. Modul yang digunakan untuk mengeluarkan pengumuman dan announcer pemberhentian kendaraan.

5. Modul untuk komunikasi wireless dengan komputer pusat jaringan sistem.

Sistem informasi penumpang yang baik adalah sistem yang menggunakan beberapa media, sehingga penumpang dengan cepat dan mudah akses ke informasi di semua tempat dimana informasi tersebut mungkin diperlukan ketika berpergian. Menurut Hamer (2016), persyaratan ini dapat dicapai dengan memperluas jangkauan sistem informasi penumpang ke semua lokasi yang penumpang mungkin gunakan, dari kereta, atau stasiun itu sendiri.

Penggunaan sistem informasi penumpang tidak terbatas untuk transportasi umum yang ada di pusat perkotaan. Sistem tersebut sering digunakan dalam bus antarkota ,pesawat dan kereta api. Sistem informasi penumpang yang menginformasikan penumpang terkait dengan pengoperasian transportasi umum tersebut. Informasi yang disampaikan antara lain:

1. Jadwal, stasiun, nomor kereta, tujuan akhir.

2. Informasi mengenai keterlambatan kereta yang mempengaruhi jadwal.

3. Informasi mengenai kondisi aktual di perjalanan

4. Pesan tentang perubahan dalam jaringan komunikasi, hiburan, dll. 


\section{Visual advertisement}

Sistem informasi penumpang dapat diimplementasikan pada:

1. Display tampilan yang terdapat pada stasiun atau kereta.

2. Internet dengan web browser, ponsel, dan perangkat mobile dengan akses internet.

\subsection{Arsitektur Passenger Information System}

Passenger Information System merupakan komunikasi utama yang menghubungkan antar moda transportasi dan penumpangnya. Teknologi Passenger Information System memungkinkan antar moda berkomunikasi dengan penumpang untuk menyediakan informasi mengenai lokasi dan status update secara real-time, data jadwal dan pengumuman tepat waktu ("Multimedia Passenger," 2016).

Arsitektur Passenger Information System dibagi menjadi tiga bagian yang berbeda yaitu pusat kendali, moda transportasi (kereta api atau kereta rel listrik), dan instalasi tetap (stasiun, depot, track dan terowongan). Sistem terhubung dalam jaringan Wide Area Network (WAN) yang memiliki cakupan area yang luas. Sistem bersifat scalable dan dikonfigurasi untuk jaringan kereta atau transportasi berkembang[5]. Arsitektur Passenger Information System dijelaskan pada Gambar 1.

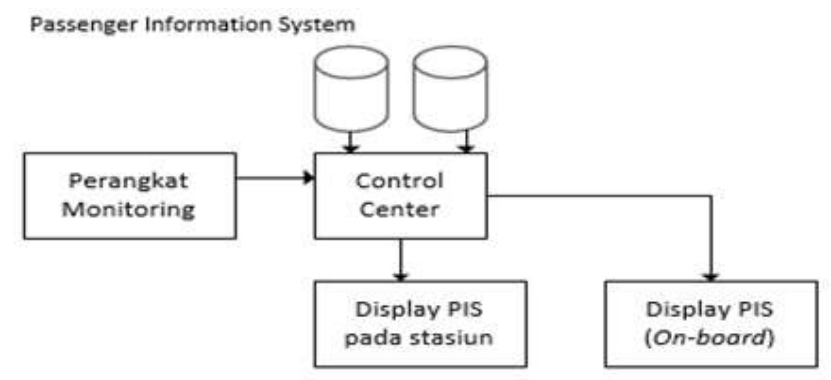

Gambar 1. Arsitektur Passenger Information System

\subsection{Display pada Passenger Information System}

\subsection{1. $L C D-T F T$}

LCD-TFT (Thin Film Transistor) merupakan jenis layar LCD yang memberikan kualitas teks, gambar dan resolusi lebih tinggi dibandingkan generasi layar LCD sebelumnya. LCDTFT banyak digunakan sebagai sistem informasi penumpang indoor dan outdoor. Display LCD-TFT dapat dikonfigurasi menjadi tampilan single-sided double-sided, atau side-by-side. Namun layar LCD-TFT mempunyai keterbatasan pada sudut pandang dan visibilitas jika berhadapan dengan cahaya matahari ("Multimedia Passenger," 2016).

\subsubsection{Variable Massage Sign}

Variable Message Signs (VMS) merupakan suatu media elektronik yang terbuat dari LED dan berfungsi untuk menampilkan informasi multimedia berbentuk text, gambar atau logo, animasi, grafik, dan lainnya. Display LED akan disambungkan ke sebuah controller atau komputer yang terdapat aplikasi yang berfungsi untuk menerima file multimedia dari komputer server di ruang kontrol dan menampilkannya pada display sesuai dengan perintah komputer server ("Introduction to Variable, " 2010).

Pesan yang ditampilkan dibatasi oleh jenis VMS yang digunakan dan konfigurasi display atau matriks. Ada tiga jenis tipe tampilan matriks, yaitu ("Introduction to Variable, " 2010): 


\section{Character Matrix}

Berisi tampilan ruang yang terpisah dibuat tersedia untuk setiap huruf dari pesan teks. Sebuah konfigurasi matriks karakter 6 horizontal dan 2 vertikal hanya memiliki 12 ruang karakter.

\section{Line Matrix}

Pada display tidak ada pemisahan fisik antara karakter dalam satu baris teks. Namun, dalam matriks baris masih tetap pemisahan horizontal antara baris yang berbeda dari teks.

3. Full Matrix

Tidak mengandung pemisahan fisik antara karakter individu atau garis dalam pesan. Sebuah pesan dapat ditampilkan pada setiap ukuran dan lokasi selama itu adalah dalam ruang display.

\subsubsection{Kiosk}

Kiosk adalah terminal komputer yang menggunakan hardware khusus dan software yang dirancang menyediakan informasi publik dan aplikasi untuk komunikasi, perdagangan, hiburan, dan pendidikan. Oleh karena itu, kiosk mulai banyak digunakan untuk sistem informasi layanan penumpang ("Restaurant Ordering, " 2016). Kiosk memungkinkan pengguna berinteraksi dan menggunakan touch screen, suara, dan video.

\subsection{Kereta Rel Listrik Jabodetabek}

Hingga Oktober 2016, KCJ telah memiliki 826 unit KRL. Pada tahun 2016, rata-rata jumlah pengguna KRL per hari mencapai 850.000 pengguna pada hari-hari kerja, dengan rekor jumlah pengguna terbanyak yang dilayani dalam satu hari adalah 931.082. Sebagai operator sarana, kereta Commuter Line yang dioperasikan KCJ saat ini melayani 72 stasiun di seluruh Jabodetabek dengan jangkauan rute mencapai $184,5 \mathrm{~km}$. Tabel 1 menunjukkan peta rute KRL.

Tabel 1. Peta Rute KRL Jabodetabek

\begin{tabular}{|c|c|c|c|c|}
\hline $\begin{array}{l}\text { Warna } \\
\text { Jalur }\end{array}$ & Data & Rute & $\begin{array}{l}\text { Total } \\
\text { Stasiun }\end{array}$ & Status \\
\hline Merah & Jakarta - Bogor/ Depok & Jakarta Kota ke Bogor & 24 & PP \\
\hline Biru & Jakarta - Bekasi & Jakarta Kota ke Bekasi & 16 & PP \\
\hline \multirow{4}{*}{ Kuning } & \multirow{4}{*}{$\begin{array}{l}\text { Lingkar Jatinegara - } \\
\text { Kampung Bandan - } \\
\text { Depok/Bogor/Nambo }\end{array}$} & Jatinegara ke Bogor & 28 & PP \\
\hline & & Jatinegara ke Kampung Bandan & 8 & PP \\
\hline & & Kampung Bandan ke Bogor & 20 & PP \\
\hline & & Duri ke Bogor & 19 & PP \\
\hline \multirow{3}{*}{ Hijau } & \multirow{3}{*}{$\begin{array}{l}\text { Jakarta - Tangerang } \\
\text { Selatan/Bogor/Lebak }\end{array}$} & Tanah Abang ke Serpong & 8 & PP \\
\hline & & $\begin{array}{c}\text { Tanah Abang ke } \\
\text { Panjang }\end{array}$ & 11 & PP \\
\hline & & Tanah Abang ke Maja & 17 & PP \\
\hline Cokelat & Jakarta - Tangerang & Duri ke Tangerang & 11 & PP \\
\hline Pink & Tanjung Priok Line & Jakarta Kota ke Tanjung Priok & 4 & PP \\
\hline
\end{tabular}

\section{PERANCANGAN SISTEM}

Perancangan sistem menguraikan tentang analisis kebutuhan sistem informasi penumpang KRL, spesifikasi sistem sebagai landasan membangun sistem informasi penumpang KRL dan perancangan sistem informasi. 


\subsection{Display pada Passenger Information System}

Admin dapat menambahkan informasi perjalanan kereta dan dapat langsung ditampilkan dengan metode one way data binding sehingga penumpang dapat mengetahui kondisi perjalanan kereta pada saat di stasiun. Web service akan memberikan layanan klien agar dapat mengakses halaman utama website.

\subsection{Perancangan Interface Sistem Informasi Penumpang}

Gambar 2 menunjukkan perancangan user interface dari sistem informasi penumpang KRL. Gambar 3 menunjukkan perancangan user interface konten entertainment pada sistem informasi penumpang yang berisikan video informasi himbauan, iklan dan lainnya. Gambar 4 menunjukkan perancangan user interface konten dashboard pada sistem informasi penumpang yang berguna untuk memisahkan halaman user dan admin.

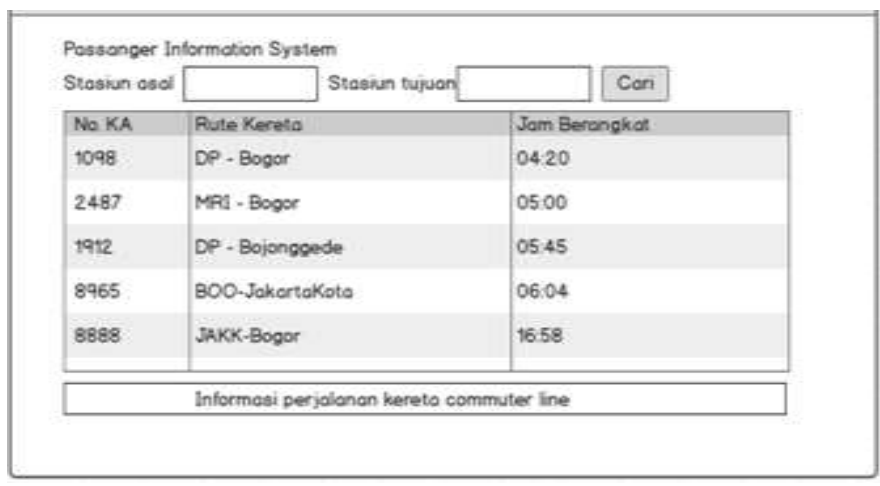

Gambar 2. Perancangan user interface dari sistem informasi penumpang KRL

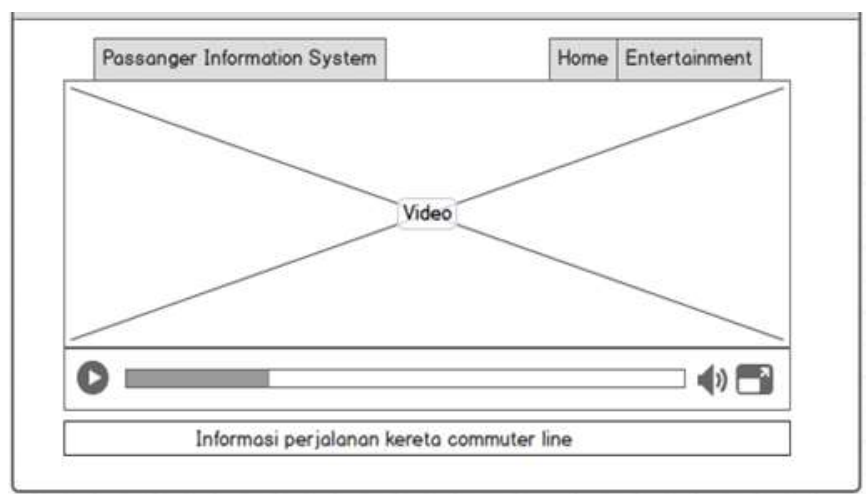

Gambar 3. Perancangan user interface konten entertainment

\section{IMPLEMENTASI DAN PENGUJIAN}

\subsection{Implementasi Rancangan}

Proses implementasi data KRL akan menjelaskan pengambilan data yang dibutuhkan untuk diproses dan ditampilkan pada sistem display ini

\subsubsection{Implementasi Perangkat Lunak}

Pada sistem display informasi penumpang ini perangkat lunak (software) yang digunakan adalah ReactJs, database Mysql, web service NodeJs dengan tambahan ExpressJs. 


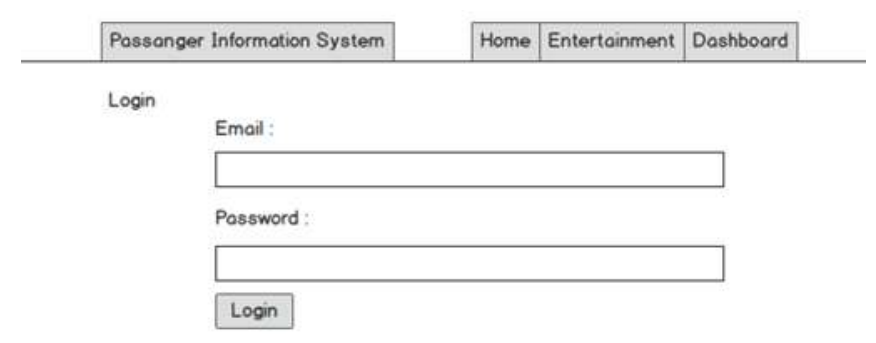

Gambar 4. Perancangan user interface konten dashboard

\subsubsection{Implementasi Database}

Tabel rute memberi arah rute, stasiun asal dan tujuan tiap kereta yang akan beroperasi. Tabel kereta berisikan nama kereta, jam berangkat, dan informasi mengenai posisi kereta pada saat beroperasi. Tabel stasiun merupakan nama stasiun, kode atau nomor urut stasiun dan jumlah rute kereta yang dilayani pada tiap harinya. Gambar 5 menunjukkan perancangan database sistem informasi penumpang.

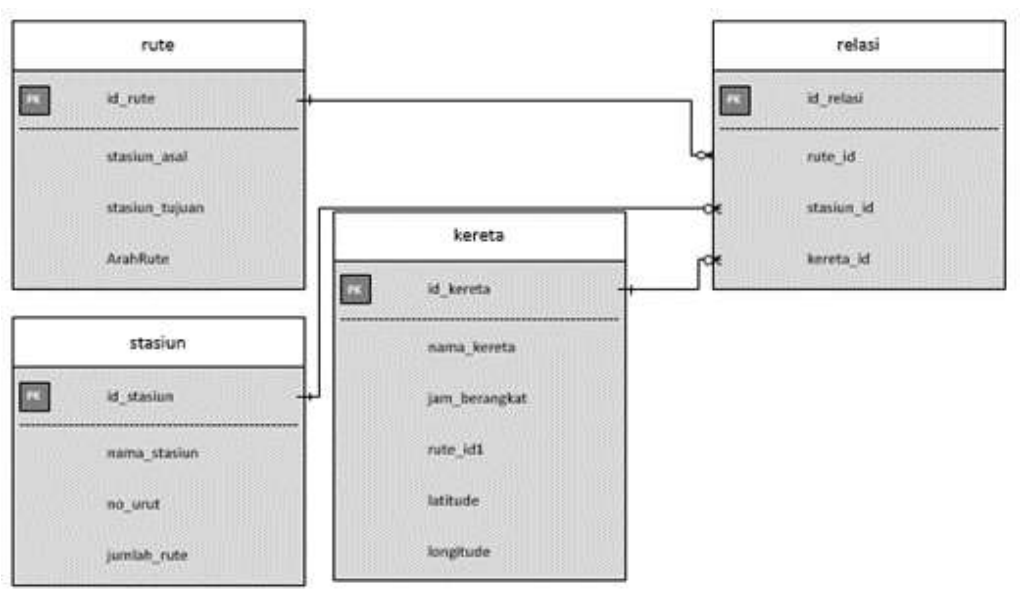

Gambar 5. Perancangan Database Sistem Informasi Penumpang

\subsubsection{Implementasi Program}

Pada bagian implementasi program ini, dilakukan pengembangan yang diakses klien dengan menggunakan NodeJs. Gambar 6 merupakan tanda bahwa web service sudah dapat melayani permintaan layanan client.

\subsection{Pengujian Sistem}

Pengujian dilakukan agar sistem ini diharapkan dapat berjalan baik tanpa ada gangguan atau kesalahan pada program sebelum sistem ini dijalankan pada sistem yang nyata. 


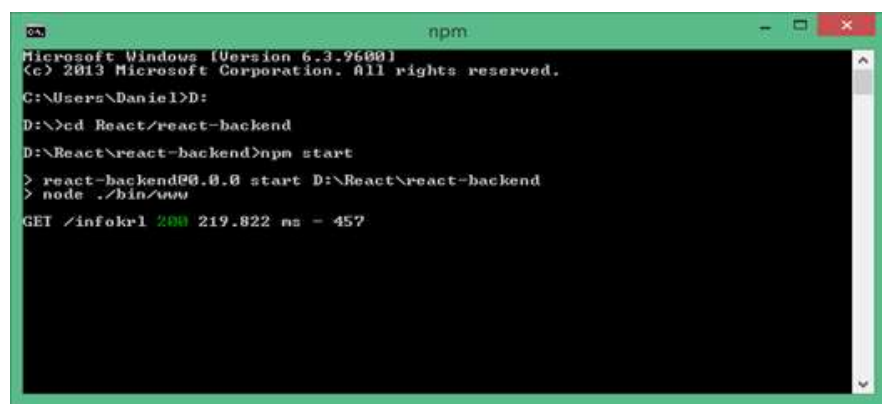

Gambar 6. NodeJS berhasil melayani request client

\subsubsection{Pengujian Web Service Sebagai Server}

Pengujian ini untuk mengetahui sistem web service server dapat berjalan sesuai dengan fungsinya. Pengujian web service server memiliki beberapa skema spesifik, seperti:

- Web service server melakukan request dan response

Web client mengirimkan request dan diterima oleh server. Server mengirimkan response informasi ke web client sehingga data informasi tersebut dapat ditampilkan. Gambar 7 menunjukkan hasil web service server dapat menerima dan mengirimkan request maupun response.

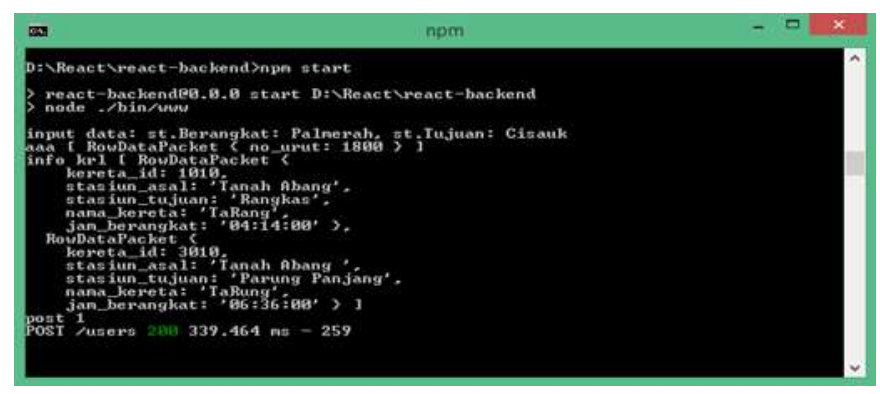

Gambar 7. Web service server dapat menerima dan mengirimkan request maupun response

- Web service server yang dituju tidak aktif

Web client mengirimkan request ke web service server, akan tetapi web service server tersebut tidak aktif, sehingga data informasi klien request tidak dapat dilihat oleh pengguna.

- Web service server tidak memberikan response

Web client mengirimkan request ke web service server, tetapi web service server tidak memberikan respon. Oleh karena itu, data informasi tidak dapat tampil pada web client. Gambar 8 menunjukkan web service server tidak memberikan response terhadap request informasi web klien.

\subsubsection{Pengujian Display}

Pengujian implementasi display yang akan digunakan. Pengujian dilakukan dengan menggunakan layar LCD, dengan menggunakan media web browser. Tabel 2 menunjukkan hasil pengujian tampilan display. 


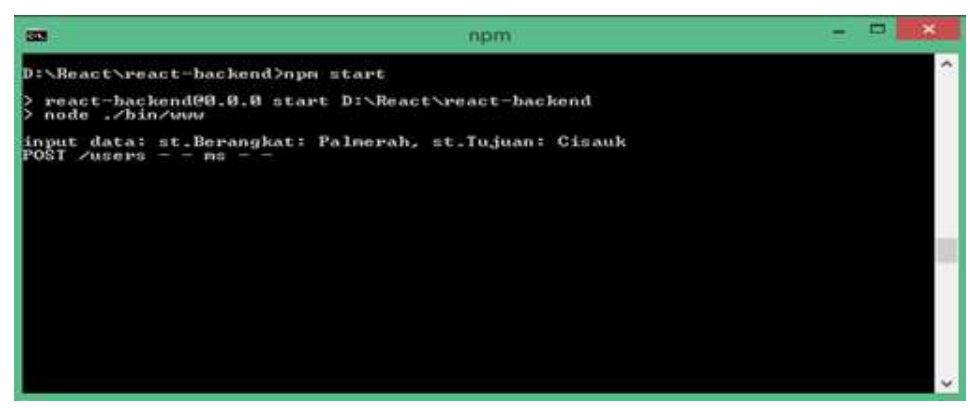

Gambar 8. Web service server tidak memberikan respon

Tabel 2. Pengujian Tampilan Display

\begin{tabular}{|c|c|c|c|}
\hline Data Masuk & Hasil yang diharapkan & Pengamatan & Kesimpulan \\
\hline Pesan informasi & Jadwal, estimasi & Informasi & {$[\mathrm{X}] \mathrm{OK}$} \\
\hline dari database. & $\begin{array}{l}\text { waktu dapat } \\
\text { ditampilkan }\end{array}$ & $\begin{array}{l}\text { perjalanan kereta dapat } \\
\text { tampil pada client }\end{array}$ & OK $[$ Not \\
\hline
\end{tabular}

\subsubsection{Pengujian Sisi Admin}

Pengujian ini dilakukan untuk dapat mengetahui menu, autentikasi login, dan input data yang hanya dilakukan oleh admin. Tabel 3 menunjukkan pengujian tampilan pada halaman admin.

Tabel 3. Pengujian Tampilan Pada Halaman Admin

\begin{tabular}{|c|c|c|c|}
\hline Data Masuk & Hasil yang diharapkan & Pengamatan & Kesimpulan \\
\hline $\begin{array}{l}\text { Pengisian form } \\
\text { input pada } \\
\text { halaman admin }\end{array}$ & $\begin{array}{l}\text { Informasi yang di- } \\
\text { input mengubah } \\
\text { dan menambahkan }\end{array}$ & $\begin{array}{lr}\text { Informasi } & \text { yang dibuat } \\
\text { atau } & \text { ditambahkan } \\
\text { mengubah } & \text { informasi }\end{array}$ & $\begin{array}{c}{[\mathrm{X}] \mathrm{OK}} \\
\left.{ }^{[}\right] \text {Not } \\
\text { OK }\end{array}$ \\
\hline & $\begin{array}{l}\text { informasi } \\
\text { database }\end{array}$ & $\begin{array}{l}\text { pada database dan } \\
\text { otomatis mengubah } \\
\text { informasi pada display }\end{array}$ & \\
\hline
\end{tabular}

\subsubsection{Pengujian Pencarian Kereta}

Pengujian pencarian kereta dilakukan untuk mengetahui mengetahui performansi dari pencarian kereta berdasarkan stasiun asal dan stasiun tujuan yang telah dirancang. Pengujian dilakukan dengan menggunakan aplikasi postman. Tabel 4 menunjukkan pembagian skenario pengujian pencarian kereta.

\subsubsection{Skenario pengujian 1}

Pada skema pengujian pertama dilakukan pada rute keberangkatan. Gambar 9 menunjukkan respon server pencarian rute keberangkatan. Pembagiannya adalah sebagai berikut :

- Stasiun tujuan dilewati oleh satu rute kereta

Penumpang dari stasiun Kebayoran dan stasiun Daru, maka server akan memberi respon informasi rute kereta yang akan menuju stasiun tujuan kereta tersebut. Kereta yang akan tampil rute Tanah Abang - Rangkas Bitung karena hanya ada satu rute kereta yang melewati stasiun tujuan penumpang.

- Stasiun tujuan dilewati oleh dua rute kereta

Penumpang dari stasiun Pondok ranji dan Parung panjang, maka server akan memberi respon informasi dua rute kereta yang akan menuju stasiun tujuan berdasarkan data dari 
database. Kereta yang akan tampil rute Tanah Abang - Rangkas Bitung, dan Tanah Abang Parung Panjang karena terdapat dua rute kereta yang dapat melewati stasiun tujuan penumpang.

- Stasiun tujuan dilewati oleh satu rute kereta

Penumpang dari stasiun Jurangmangu menuju stasiun Rawa buntu, maka server akan memberi respon informasi tiga rute kereta yang akan menuju stasiun tujuan berdasarkan data dari database. Kereta yang akan tampil rute Tanah Abang - Rangkas Bitung, Tanah Abang Parung Panjang, dan Tanah Abang - Serpong.

Tabel 4. Skenario Pengujian Rute

\begin{tabular}{clll}
\hline No & \multicolumn{1}{c}{ Nama Stasiun } & Rute 1 & $\begin{array}{c}\text { Skenario } \\
\text { Rute 2 }\end{array}$ \\
& Rute 3 \\
\hline 1 & Tanah Abang & \\
2 & Palmerah & \\
3 & Kebayoran & \\
4 & Pondok Ranji & \\
5 & Jurangmangu & \\
6 & Sudimara & \\
7 & Rawa Buntu & \\
8 & Serpong & \\
9 & Cisauk & \\
10 & Cicayur & \\
11 & Parung Panjang & \\
12 & Cilejit & \\
13 & Daru & \\
14 & Tenjo & \\
15 & Tigaraksa & \\
16 & Cikoya & \\
17 & Maja & \\
18 & Citeras & \\
19 & Rangkas & \\
\end{tabular}

\subsubsection{Skenario pengujian 2}

Pada skema pengujian kedua dilakukan pencarian rute yang lewat berdasarkan rute kepulangan. Gambar 10 menunjukkan respon server pencarian rute kepulangan. Pembagian skenario pengujian dibagi sebagai berikut:

- Stasiun tujuan penumpang dilewati oleh satu rute

Penumpang dari stasiun Maja menuju stasiun Cicayur, maka server akan memberi respon informasi satu rute kereta yang akan menuju stasiun tujuan berdasarkan data dari database.

Kereta yang akan tampil rute Rangkas Bitung - Tanah Abang karena hanya ada satu rute kereta yang melewati stasiun tujuan penumpang.

- Stasiun tujuan penumpang dilewati oleh dua rute

Penumpang dari stasiun Cicayur menuju stasiun Sudimara, maka server akan memberi respon informasi dua rute kereta yang akan menuju stasiun tujuan berdasarkan data dari database. Kereta yang akan tampil rute Rangkas Bitung - Tanah Abang, dan Parung Panjang - Tanah Abang Karena terdapat dua rute kereta yang dapat melewati stasiun tujuan penumpang. 
- Stasiun tujuan penumpang dilewati oleh tiga rute

Penumpang dari stasiun Jurangmangu menuju stasiun Rawa buntu, maka server akan memberi respon informasi tiga rute kereta yang akan menuju stasiun tujuan berdasarkan data dari database. Kereta yang akan tampil rute Rangkas Bitung - Tanah Abang, Parung Panjang - Tanah Abang, dan Serpong - Tanah Abang

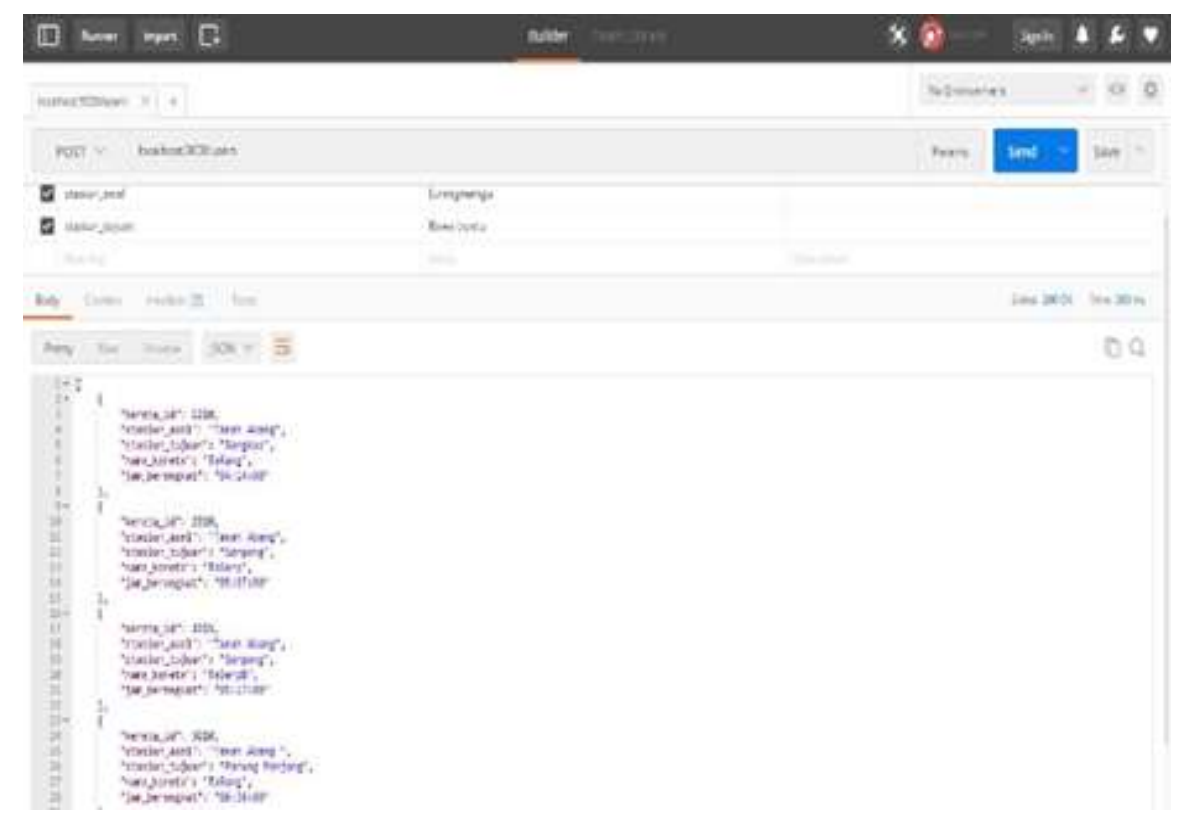

Gambar 9. Respon server pencarian rute keberangkatan

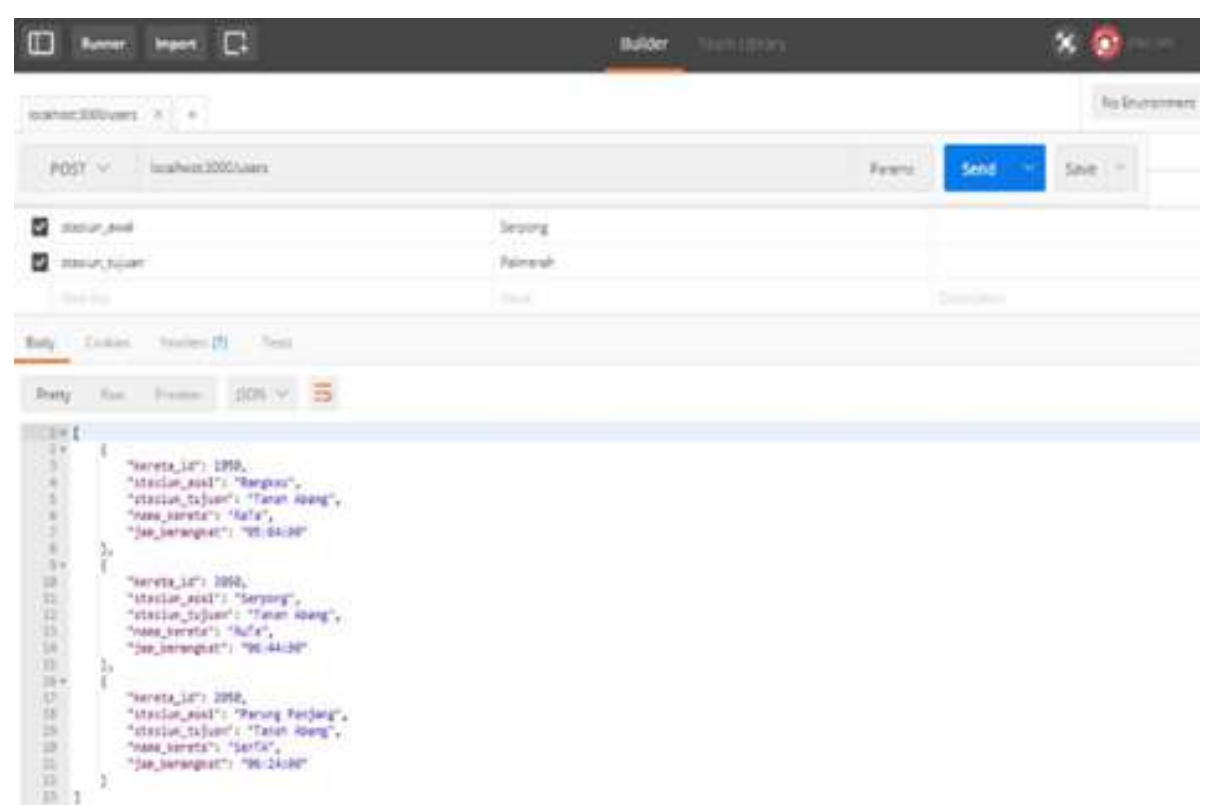

Gambar 10. Respon server pencarian rute kepulangan

\section{KESIMPULAN}

Berdasarkan hasil dari perancangan dan pengujian, maka dapat diambil kesimpulan sebagai berikut:

1. Implementasi web service yang bekerja sebagai server dan client dapat terkoneksi sehingga dapat memberikan informasi yang detail kepada penumpang. 
2. Admin dapat menambahkan, mengubah, dan memperbarui informasi untuk sistem informasi penumpang.

Sistem informasi penumpang yang dirancang pada tampilan display adalah pengembangan dari sistem informasi penumpang manual sebelumnya. Oleh sebab itu, pengembangan ke arah yang lebih baik perlu dilakukan untuk meningkatkan efektifitas dari kinerja pengguna dalam menjalankan tugasnya. Adapun saran dalam terhadap pengembangan terhadap sistem display informasi penumpang ini sebagai berikut:

1. Mengubah sistem tampilan jadwal menjadi otomatis tergantikan bila jadwal kereta telah masuk ke stasiun.

2. Menambahkan konten entertainment secara dinamis agar dapat memutar video sesuai dengan lokasi yang dilewati oleh kereta.

Menambahkan tampilan pada sisi admin dengan sistem tracking pada setiap kereta yang sedang beroperasi pada masing-masing jalur.

\section{DAFTAR PUSTAKA}

The-Alcatel-Lucent Integrated Control and Management System. (2016, November 9). Retrieved from http://enterprise.alcatel-lucent.com/assets/documents/SBG56 77110202_ICMS_EN_Brochure.pdf

Multimedia Passenger Information System. (2016, November 13). Retrieved from http://www.aesys.com/LED-signs-and-LED-display/bus-systems/on-board-systems/ multimedia-passenger-information-system

Introduction to Variable Massage Signs. (2010). Departement of Transportation Washington State Student Handbook., (pp. 2-12).

Matsumoto, K., Nakada, K., \& Azuma, K. (2016, October 10). Development of On-board Passenger Information Display. Retrieved from http://www.hitachi.com/rev/pdf/ 2014/r2014_10_109.pdf

Hamer, P. (2016, November 2016). Pre-Investment Study of the Passenger Information System for the Airport Poznan-Lawica Sp.ZO.O. Retrieved from http://www.champions-project.de/public_docs/4.2.6\%20PreInvestment\%20study\%20Poznan.pdf

Restaurant Ordering System Over Interactive Kiosk. (2016, November 24). Retrieved from http://www.essay.uk.com/essays/information-technology/restaurant-ordering-systemover-interactive-kiosk 